\title{
Synthesis of New Chiral Chromonic Lyotropic Liquid Crystal Based on Perylenebis(dicarboximide)
}

\author{
Jaishri J. Naidu, Yun-Ju Bae, Kwang-Un Jeong, Seung Hee Lee, Shinwoong Kang, and Mỵong-Hoon Lee \\ Department of Polvmer Nano Science Technology, Chonbuk National Eniversity, \\ Chonju, Chonbuk 561-756. Korea. 'E-mail: mhleezo ochonbuk ackr \\ Liquid Crustal Institute, Kent State Universitw, Kent, Ohio $+42+2,6 \mathrm{SA}$ \\ Received August 11, 2008, Accepted February 17, 2009
}

Key Words: Chiral lyotropic chromonic LCs. Cholesteric fingerprint texture. Chiral nematic $\left(\mathrm{N}^{*}\right)$ phase

Lyotropic chromonic liquid crystals (LCLCs) represent a special class of lyotropic mesophases markedly different from the conventional amphiphilic mesogens. ${ }^{1-3}$ LCLCs are composed of plank-like molecules with polyaromatic central core and hydrophilic ionic groups at the periphery. Because of the hydrophobic nature of the aromatic central core and the hydrophilic periphery, the molecules assemble into stacks with degenerated molecular orientation in the molecular plane to form chromonic nematic $(\mathrm{N})$ phase. In the $\mathrm{N}$ phase. the columnar aggregates align parallel to each other but show no long-range positional correlations. The variety of possible geometries of aggregations is enriched by the fact that the molecular planes can adopt different orientations with respect to the axis of the aggregates.

Applications of chromonic liquid crystals are relatively unexplored. Potential applications reported for chromonic liquid crystals include the fabrication of light-harvesting devices $^{4}$ and coatable polarizers which are fabricated by aligning liquid crystals vio photo-alignment or mechanical shearing techniques. ${ }^{5}$ In both cases, an important criterion for generating high performance polarizing films is the selforganization of dichroic dyes into a highly ordered orientation. Chromonic liquid-crystalline phase is subsequently dried to give an anisotropically oriented solid phase. The structureproperty relationships of chromonic liquid crystals are not clearly understood despite the identification of many chromonic mesogens. Furthermore. despite the importance of the LCLCs in various applications such as optically oriented films. bio-sensors and mimicking of nucleic acids chromonic mesogens having optically active center have been studied rarely. Besides. the most of studies concerns a chiral phase attained by doping a chromonic $\mathrm{N}$ phase with a chiral dopant ${ }^{6}$ rather than a chiral group directly attached to a mesogenic core.

Perylene dyes cover the whole range of the visible spectnum and find applications in conventional uses as well as in high-tech applications. ${ }^{8.13}$ Especially, 3.4:9.10-pery lenebis(dicarboximides) are generally referred as a functional dy'e due to their electro-optic nature such as photo-conductivity and fluorescence in addition to the unique optical absorption property. The perylene dyes find wide applications in optical films. photo-conducting materials, sensors and electroluminescent displays. Recently. LCLCs based on pery lene core have attracted much attention because the anisotropic orientation of molecules with $\pi-\pi$ stacking of aromatic core can exploit their intrinsic properties most efficiently.

In this paper. we report the first synthesis of a perylene-based chiral mesogen for LCLC as shown in Figure $\mathrm{I}$, and discuss its lyotropic chromonic liquid cry stalline behavior. The synthesis of (S)-(-)-2-aminometlyyl-1-ethylpy rrolidine 3.4:9.10-perylenebis(dicarbovimide) (1) was carried out by refluxing perylene-3.4:9,10-tetracarboxylic anlydride with chiral (S)(-)-2-aminomethyl)-1-ethylpyrrolidine in dimethylsulfoxide (DMSO) to give a dark red perylene diimide solid in ligh yield after purification. ${ }^{12}$ Dilydroclloride salt (2) of 1 was prepared by addition of excess amount of conc. $\mathrm{HCl}$ with subsequent removal of rennant $\mathrm{HCl}$. The compound 1 was not soluble in most of organic solvents. slightly soluble in methylene chloride and chloroform, and only soluble in acids such as $\mathrm{CF}_{3} \mathrm{COOH}$ and $\mathrm{HCl}$. When converted to a salt form

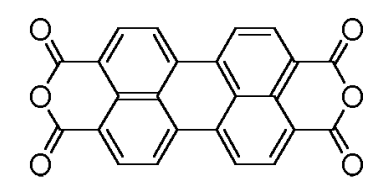<smiles>CCN1CCC[C@H]1CN</smiles>
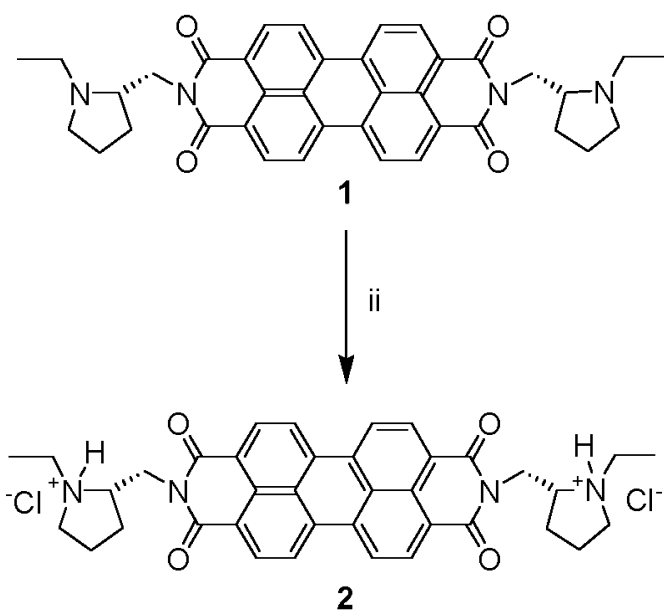

Figure 1. Synthetic scheme of new chiral LCLC. i) in DMSO, $70^{\circ} \mathrm{C}$, $26 \mathrm{~h}$, ii) conc. HCl 


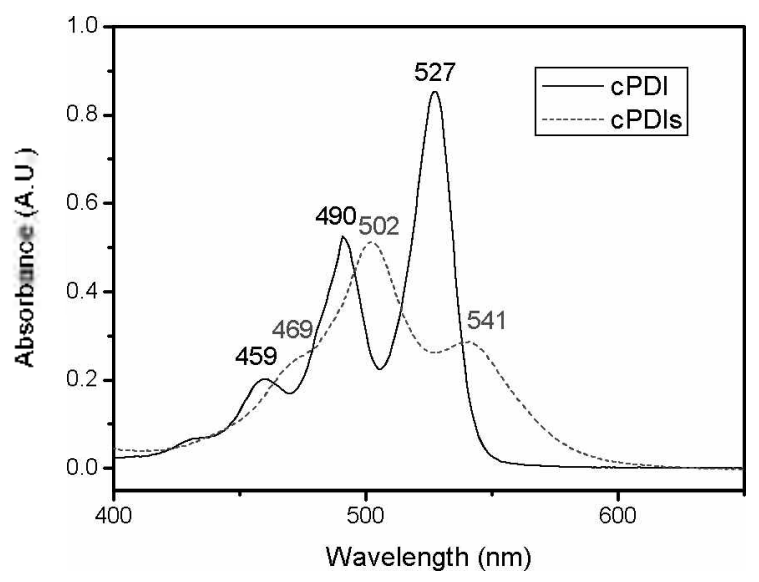

Figure 2. Visible spectra of 1 (solid) in $\mathrm{CHCl}_{s}\left(2 \times 10^{-7} \mathrm{M}\right)$, and 2 (dot) in water $\left(1.7 \times 10^{\circ} \mathrm{M}\right)$.

with $\mathrm{HCl}$, however, it became soluble in water. Compound 1 exhibited strong fluorescence with violet color in methylene chloride or chloroform solution. The structure of compound 1 was characterized by ${ }^{1} \mathrm{H}-\mathrm{NMR},{ }^{13} \mathrm{C}-\mathrm{NMR}, \mathrm{R}$ and UV/vis spectroscopy. The results of ${ }^{1} \mathrm{H}-\mathrm{NMR}$ and ${ }^{13} \mathrm{C}-\mathrm{NMR}$ spectroscopic characterization are listed in reference 13. High resolution mass spectroscopic result also confirmed the structure of compound 1. IR peaks at 1692 and $1664 \mathrm{~cm}^{-1}$ indicated the complete formation of imide bond. The visible absorption spectra for compound $1\left(2 \times 10^{-} \mathrm{M}\right)$ in clloroform and $2\left(1.7 \times 10^{6} \mathrm{M}\right)$ in distilled water are shown in Figure 3. Compound 1 showed a $\lambda_{\max }$ at $527 \mathrm{~nm}$ with two smaller absorptions at 490 and $459 \mathrm{~nm}$, which are characteristic of free perylenebis(dicarboxinude). ${ }^{13}$ For corresponding salt 2 , we observed the peak at $527 \mathrm{~nm}$ which is most likely due to absorption of the monomeric dye molecules ${ }^{14}$ shifted to red with significantly decreased intensity. The relative intensity of the other two peaks at 490 and $459 \mathrm{~mm}$ increased with red-shift. This suggests that the salt form exists as a dimer and higher aggregates in aqueous solution even at dilute concentration. which is referred as isodemic.

Aqueous solutions of compound 2 under polarized optical microscope (POM) exhibited various liquid-crystalline textures as shown in Figure 3. A cholesteric fingerprint texture was observed at $35.8 \mathrm{C}$ for the sample of $9 \mathrm{wt} \%$ concentration (Fig. 1a). This clearly indicates a formation of chiral nematic (N) phase due to helical stacking of chiral mesogens. The spacing of the bands was measured to be ca. $2.6 \mu \mathrm{m}$ which corresponds to half of the pitch. When the sample was slightly heated. the cholesteric fingerprint texture mixed with the isotropic phase as shown in Figure $1 \mathrm{~b}$. which is defined as a biphasic state where a nematic phase and an isotropic phase coexist. Oily streaks texture which is another characteristic of chiral nematic $\left(\mathrm{N}^{-}\right)$phase was also observed (Fig. lc). In addition. ribbons and herringbone textures were found for samples with high concentration indicating the existence of hexagonal (M) phase (Fig. Id and le). Marbled texture of nematic $\left(\mathrm{N}^{*}\right)$ phase was also noticed as shown in Fig. If.

Based on the temperature-controlled POM observation of aqueous solution of compound $\mathbf{2}$ in a sealed glass cell, we successfully obtained a phase diagram of the chiral LCLC in temus of concentration rs. temperature as shown in Figure 4. The concentration of aqueous solution was precisely determined by thermogravimetric analyses (TGA) from the
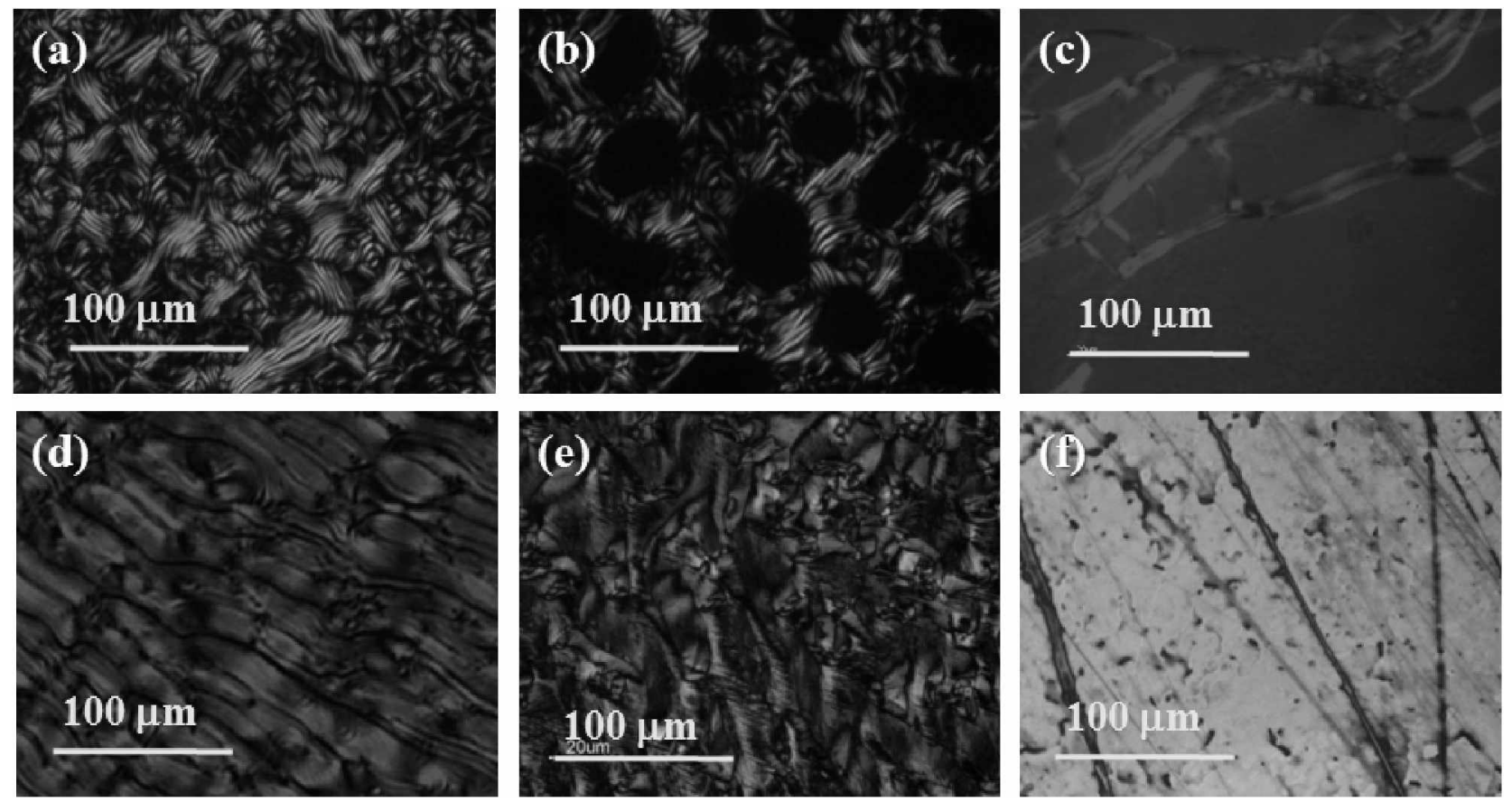

Figure 3. POM textures of compound 2 in aqueous solution: (a) Cholesteric fingerprint testure of cholesteric $\left(\mathbb{N}^{*}\right)$ phase $\left(9\right.$ wt $\%$ at $\left.35.8^{\circ} \mathrm{C}\right)$; (b) Cholesteric fungerprint texture of cholesteric ( $\mathrm{N}$ ) phase mixed with isotropic phase observed at the same location of $\left(\right.$ a) $\left(9 \mathrm{ct} \%\right.$ at $\left.45.7^{\circ} \mathrm{C}\right)$; (c) Oily streaks texture of cholesteric $\left(\mathrm{N}^{-}\right)$phase $(30 \mathrm{wt} \%)$; (d) Ribbons of hexagonal (M) phase (15 wt \%); (e) Herringhone texture of hexagonal (M) phase $(27 \mathrm{wt} \%)$; (f) Marbled texture $\left(\mathrm{N}^{*}\right)(9$ wt \%). 


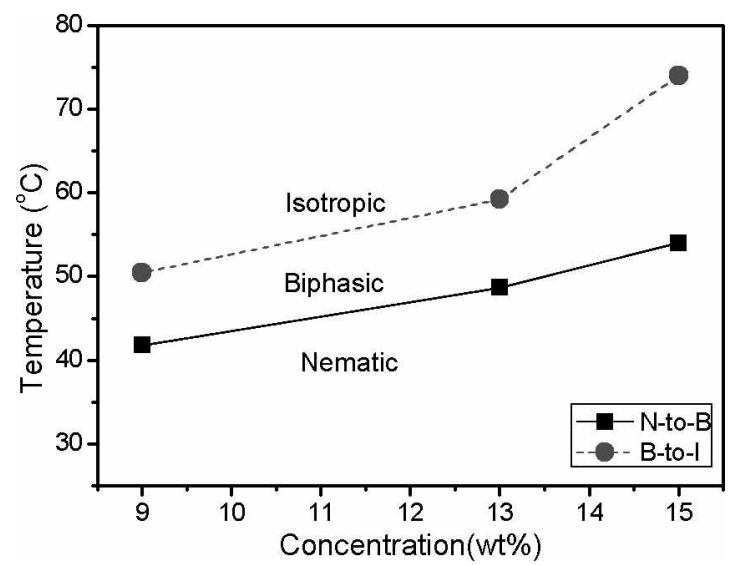

Figure 4. Phase diagram of compound 2 in aqueous solution.

amount of exaporated water when heated up to $250^{\circ} \mathrm{C}$. Phase transitions of LCLC with respect to temperature change can be observed in the range of $9-15 \mathrm{wt} \%$. As the temperature increased from room temperature. nematic phase $(\mathrm{N})$ turned into a biphasic state in which a nematic $\left(\mathrm{N}^{*}\right)$ phase coexists with isotropic phase, and subsequently changed to isotropic phase. At higher concentration than $20 \mathrm{wt} \%$. further phase transition from nematic phase was not detected up to the boiling temperature of water $\left(>100^{\circ} \mathrm{C}\right)$.

In summary, we report the first example of chiral lyotropic chromonic liquid crystal (LCLCs) based on perylenebis(dicarboximide) core. Strncture of chiral LCLC was characterized by ${ }^{1} \mathrm{H}-\mathrm{NMR}$. ${ }^{13} \mathrm{C}-\mathrm{NMR}$. FT-IR, UV-vis spectrometer and POM. Aqueous solution of the chiral salt exhibited characteristic textures of chiral nematic $\left(\mathrm{N}^{-}\right)$phase such as cholesteric fingerprint and oily streaks under POM. We derived a phase diagram based on the phase transitions monitored by POM at various concentrations and temperature. Further stnictural analy'ses including high-resolution sy nchrotron $\mathrm{X}$-ray diffraction studies are now in progress. which will be published in due course

\section{Experimental Section}

(S)-(-)-2-Aminomethyl-1-ethylpymolidine 3,4:9,10-perylenebis(dicarboximide) (1). In a $100 \mathrm{~mL}$ round bottom flask. (S)-(-)-2-aminomethyl-1-ethylpy rrolidine $(3.40 \mathrm{~mL}, 22.95$ mmol) was added to $3.0 \mathrm{~g}$ (7.65 mmol) of perylene-3.4:9.10tetracarboxylic anlydride dissolved in $50 \mathrm{~mL}$ of DMSO. The mixture was stirred at $70{ }^{\circ} \mathrm{C}$ for $26 \mathrm{~h}$. After cooling, the reaction mixture was filtered and the dark red solid washed with $\mathrm{MeOH}$ and ethyl acetate repeatedly. The solid was dried under vacuum to obtain compound 1 in $89.4 \%$ yield. ${ }^{1} \mathrm{H}-\mathrm{NMR}$ (400) $+\mathrm{H} . J=8.1 \mathrm{~Hz})+.92-4.78(\mathrm{dd} 4 \mathrm{H})+4.52(\mathrm{~m} .2 \mathrm{H}) .+.02(\mathrm{~d}$. $+\mathrm{H}) .3 .65(\mathrm{q} .4 \mathrm{H}), 2.6(\mathrm{t}, 4 \mathrm{H}), 2.2(\mathrm{t}, 4 \mathrm{H}), 1.65(\mathrm{t}, 6 \mathrm{H})$ : ${ }^{13} \mathrm{C}-\mathrm{NMR}\left(400 \mathrm{MHz}\right.$, in $\left.\mathrm{CF}_{3} \mathrm{COOD}\right)$ : ò 159.4, 133.9. 133.0 .
$130.9,129.2 .126 .5 .124 .5,57.8,55.4 .46 .7 .38 .0 .29 .3,23.4$, 13.6: FT-IR (KBr): 2957, 2789, 1692, 1664, 1593, 1351, 1245 $\mathrm{cm}^{-1}$ : HRMS-FAB $\left[\mathrm{MH}^{-}\right]$cald. $\mathrm{m} / \mathrm{z}(6 \mathrm{l} 2.27)$, found $\mathrm{m} / \mathrm{z}$ (612.28).

Dihydochloride salt (2) of compound 1. Compound 2 was prepared by completely dissolving contpound 1 in conc. $\mathrm{HCl}$, with subsequent evaporation of remaining $\mathrm{HCl}$ by rotary evaporator under reduced pressure. The resulting solid was dried in vacuun oven at room temperature for $2+\mathrm{h}$.

Aclonowledgments. This work was supported by the Korea Science and Engineering Foundation (KOSEF) grant funded by the Korea government (MEST) (R01-2007-000-20050-0). JJN acknowledges for the financial support by grant of the Post-doc Program. Chonbuk National University 2007. YJB and SHL also thank to Polymer BIN Fusion Research Center at Chonbuk National University

\section{Refeiences}

1. Lydon, T. In Handbook of Liquid Cnustals; Demus, D.: Goodby, I:: Gray, G. W.: Spiess, H.-W.: Vill, V., Eds.; Wiley-VCH: Weinheim, 1998; V.2B, pp 981-1007 and references therein.

2. (a) Lydon. J. Cum Opin. Colloid hnterface Sci. 1998, 3, 458. (b) ibid. $2000,+8,480$.

3. Vasilevshaya, A. S.; Generalova, E. V.; Sonin , A. S. Russ. Chem. Rev $1989,58,904$

4. Gustand, D; Moore, T. A. Science 1989, 24t, 35

5. (a) Ichimura, $\mathrm{M} ;$ Kudo, K. M: Akivama, H.; Ishizuki, N. Langnuir 1995, 11, 2341. (b) Matsunaga, D., Tamaki, T.; Akiyama, H.; Ichimura, K. Adw. Hater: 2002, 14,1477 . (c) Tam-Chang, S.-W.: Seo, W.; Iverson, I. K.: Casey, S. M. Angew: Chem, int. Ed. 2003, 42, 897. (d) Iverson, I. K.: Tam-Chang. S.-W. J. fm Chem. Soc. 1999, 121, 5801 . (e) Carson, T. D.; Seo, W.: Tam-Chang, S.W.; Casey, S. M. Chem. Mater 2003, 15, 2292. (f) Iverson, I. K.; Casey, S. M.: Seo, W.: Tam-Chang. S.-W.: Pindzola, B. A. Lamgmir 2002, $18,3510$.

6. (a) Lee, H.: Labes, M. Aol Cnst Liq. Civst 1982, 84, 137 (b) Goldtarb, D.: Labes, M. M.: Luz, Z; Poupko, R. Mol Cinst. Liq. Cinst. 1982, 89, 259

7. Seo, W. Lissertation, University of Nevada, Reno, 2004

8. Loufty, H. O.; Hor, A. M.; Kazmaler, P.; Tam, M. J. Imag. Sci. $1989,33,151$.

9. (a) Seybold, G.; Wagenblast, G. Dves Pigm. $1989,11,303$. (b) Langhals, H. Nachr. Chent Tectnol Lab. 1980, $28,716$.

10. Schlettwein, D.; Wohrle, D;: Karmann, E.; Melville, U. Chem. Hater $1994,6,3$.

11. ONeil, M. P.: Niemczyk, M. P.: Svec, W. A.: Gosztola, D.; Gaines. G. L.: Wasielewski, M. R. Science 1992, 257,63.

12. (a) Sadrai, M.: Hadel, L: Sallers, R. R:; Husain, S.; KroghTespersen, K. Westbrook, J. D; Bird, G. R. J. Phys. Chem. 1992. 96,7988 (b) Gvishi, R.: Reisfeld, R.; Burshtein, Z. Chem. Phus. Lett. 1993, 213, 338 .

13. (a) Langhals, H.: Ismael, R. Eur. J. Org. Chem. 1998, 1915. (b) Li. A. D. Q.: Wang, W.: Wang. L.-Q. Chem. Em. J. 2003, 9, 4594. (c) Chen, Z.; Stepanenko, V.; Dehm, V.; Prins, P:; Siebbeles, L. D. A; Seibt, I; Marquetand, P.; Engel, V.; Garthner, W. F. Chem. Eur. J. 2007, 13,436.

14. Ford. W. E. J. Photochem. 1987, 37, 189. 